\title{
AYUSH-64 as an adjunct to Standard Care in mild to moderate COVID-19: An open-label randomized controlled trial in Chandigarh, India
}

Harbans Singh ${ }^{1}$, Sumit Srivastava ${ }^{2}$, Babita Yadav ${ }^{3}$, Amit K Rai ${ }^{3}$, Sophia Jameela ${ }^{3}$, Sanuj

Muralidharan $^{2}$, Rijin Mohan ${ }^{2}$, Shikha Chaudhary ${ }^{2}$, Richa Singhal ${ }^{3}$, Rakesh Rana ${ }^{3}$, Shruti

Khanduri $^{3}$, Bhagwan S Sharma ${ }^{3}$, Bhogavalli Chandrasekhararao ${ }^{3}$, Narayanam Srikanth ${ }^{3}$, Sarika Chaturvedi $^{4}$

\section{Author's Affiliation}

1. Central Ayurveda Research Institute, Patiala, Punjab, India

2. Shri Dhanwantry Ayurvedic College and Hospital, Chandigarh, India

3. Central Council for Research in Ayurvedic Sciences, Ministry of Ayush, Govt. of India.

4. Dr. D Y Patil Vidyapeeth, Pune, Maharashtra, India

Source of Funding: Central Council for Research in Ayurvedic Sciences, Ministry of Ayush, Govt. of India

Conflict of Interest: The authors declare that they have no known competing interests.

\section{Corresponding Author:}

Dr. Amit Kumar Rai

Central Council for Research in Ayurvedic Sciences, Ministry of Ayush, Govt. of India

61-65, Institutional Area, Opposite D-Block, Janak Puri, New Delhi-110058, India

Email: dr.amitrai1983@gmail.com

Phone number: 9105134783 


\title{
AYUSH-64 as an adjunct to Standard Care in mild to moderate COVID-19: An open-label randomized controlled trial in Chandigarh, India
}

\begin{abstract}
Background

Interest in the use of traditional medicine systems such as Ayurveda to manage COVID-19 cases is increasing. However, there is limited evidence on the safety and efficacy of administering Ayurveda interventions as add-on to the standard care for COVID-19.
\end{abstract}

\section{Objective}

To explore the therapeutic efficacy and safety of AYUSH-64 as an add-on to standard care in the management of mild to moderate stage COVID-19.

\section{Methods}

An open-label randomized controlled trial was carried out at Dhanwantry Ayurvedic Medical College and Hospital, Chandigarh, India. Eighty participants with mild to moderate stage COVID-19 were randomly allocated into AYUSH-64 add-on group and control group in 1:1 ratio. Participants in the AYUSH-64 add-on group received two tablets (500 $\mathrm{mg}$ each) three times daily for 30 days along with conventional standard care that included Paracetamol, Cetirizine, Vitamin C, and Azithromycin. The control group received standard care alone. The primary outcome assessed was the proportion of participants with clinical recovery and negative RT-PCR test for COVID-19 at scheduled follow-up visits on day 7, 15, 23, and 30. Additionally, change in pro-inflammatory markers- IL-6, D-dimer, CRP, Serum Ferritin, Pro-calcitonin, change in metabolic functions- serum LDH, BNP, Creatine kinase, liver enzymes, renal function and HRCT chest and incidence of adverse drug reaction/serious adverse event were assessed.

\section{Results}

Of the 80 participants included in the study, 74 (37 participants in each group)contributed to the final analysis. Statistically significant difference was observed in the proportion of participants with clinical recovery in the AYUSH-64 add-on group $(p<0.001)$ at each of the scheduled 
follow-up visits. Further, all the participants in the AYUSH-64 add-on group clinically recovered by day 23 compared to 32.4 per cent in the control group. The mean duration for clinical recovery in the AYUSH-64 add-on group (5.8 \pm 2.67 days) was less as compared to control group (10.0 \pm 4.06 days). The proportion of participants who turned RT-PCR negative for COVID-19 on day 7, 15, and 23 were 81.8, 94.5, and 100 per cent in the AYUSH-64 add-on group, and 79.4, 94.5, and 97.2 per cent in the control group, however, the difference observed was statistically not significant $(\mathrm{p}=0.314)$. The proportion of participants with improvement in HRCT chest was statistically significant in the AYUSH-64 add-on group $(\mathrm{p}=0.031)$ unlike in the control group ( $\mathrm{p}=0.210)$. Similar reductions in most inflammatory markers measured (IL-6, CRP, Serum ferritin, LDH, BNP, and Troponin T) on day $30(\mathrm{p}<0.05)$ were observed in both groups except that in the AYUSH-64 add-on group, significant reduction was also observed in the Ddimer level. None of the participants developed any complications nor were any significant study drug related Adverse Drug Reactions (ADR) and Adverse Events (AE) observed.

\section{Conclusion}

AYUSH-64 as adjunct to standard conventional care is safe and hastens clinical recovery in adult patients with mild to moderate COVID-19.

Trial Registration: Clinical Trial Registry of India - CTRI/2020/05/025214

Keywords: Ayurveda, COVID-19, Pandemic, Complementary medicine, Viral disease 


\section{INTRODUCTION}

COVID-19 is the third known epidemic caused by highly pathogenic human coronavirus in the last two decades after Middle East Respiratory Syndrome (MERS) in 2012 and Severe Acute Respiratory Syndrome (SARS) in 2003. It has afflicted more than 188 million people worldwide and around 4.06 million deaths have been reported globally till July 16, 2021[1]. It can present as asymptomatic or mild to moderate illness to a severe pneumonia leading to a potentially fatal acute respiratory distress syndrome [2]. As per World Health Organization, about 80 per cent of the COVID-19 cases are asymptomatic or mild to moderate; 15 per cent cases have severe disease; and 5 per cent progress to a critical stage with complications [3]. Elderly population, individuals with co-morbidities and frontline healthcare workers are at the highest risk for developing COVID-19. Recently, increasing incidence of COVID-19 in younger adults and children has also been observed [4]. The physical, psychological, social, and economic consequences of the pandemic along with the considerable morbidity and mortality have affected the world in the most unprecedented manner. This outbreak of the COVID-19 pandemic has challenged the healthcare systems globally. Several countries across the globe again witnessed a rise in COVID-19 cases in 2021, comparable to or worse than the peak touched during 2020. Apart from vaccines, significant efforts have been made to develop prophylactic and therapeutic interventions against COVID-19. As of now, no approved therapeutic options are available for the management of COVID-19. The current strategy of conventional medicine is broadly based on the repurposing and repositioning of existing medications and recommends them with symptomatic support. On the basis of published empirical evidence, several therapeutic interventions such as anti-viral, anti-malarial, anti-inflammatory, and monoclonal antibodies

have been proposed, however, the clinical outcomes observed in clinical trials are not very promising [5-7].

There is growing interest in scientifically exploring the potential of Indian traditional medicine systems such as Ayurveda to manage asymptomatic and mild to moderate COVID-19 cases [8]. Further, integrating Ayurveda with conventional medicine could offer a novel, and cost-effective approach, to reduce the disease burden and assist the over-burdened healthcare infrastructure. Traditional Chinese Medicine has been found to be effective in the management of SARS-CoV-2 infection [9]. Repurposing Ayurveda interventions for early-stage COVID-19 is felt needed, 
given that their traditional use has established safety; and experimental studies have demonstrated their immunomodulating, anti-inflammatory, anti-oxidant properties, and anti-viral activity [10-17]. The Government of India has also supported the use of Ayurveda interventions in early-stage COVID-19 [18] considering practice-based evidence and preliminary studies while underscoring the need for more studies on these interventions.

Hence, this study was designed to test the hypothesis that adding the Ayurveda intervention, AYUSH-64, to standard care is superior to standard care alone in improving the clinical status of patients with mild to moderate COVID-19. The trial drug, AYUSH-64, is a polyherbal formulation with proven efficacy in infective febrile conditions such as malaria, microfilaremia, chikungunya, and influenza with no safety issues observed in published clinical studies [19, 2023]. Furthermore, previous experimental studies suggest that the constituents of AYUSH-64 might exert immunomodulating, anti-inflammatory, and antioxidant activities [24-29]. These effects could halt the intense inflammatory responses in COVID-19 that cause progression to significant morbidity. AYUSH-64 was repurposed for COVID-19 in this study based on a previous clinical study that showed AYUSH-64 was effective in Influenza like Illness (ILI) and a molecular docking study that revealed 35 phytoconstituents isolated from AYUSH-64 demonstrated anti-viral activity against SARS-CoV-2 [19, 30].

\section{METHODS}

\section{Study Design}

This study was a single centre, open-label, randomized controlled trial with allocation in 1:1 ratio.

\section{Study Setting}

The study was conducted at Shri Dhanwantry Ayurvedic College and Hospital, Chandigarh, India. The institute has been designated as an isolation centre for COVID-19 providing medical care to patients who have been clinically assigned as either asymptomatic or mild to moderate COVID-19 and with a lower risk of severe COVID-19. The study intervention was administered by the Ayurveda physician deputed at the study centre. The study was conducted in collaboration with Central Ayurveda Research Institute for Respiratory Disorders, Patiala, Punjab, India during June to August 2020. 


\section{Participants}

Eligible for participation in this study were patients aged 18 to 75 years, who tested RT-PCR positive for COVID-19 and were categorized as mild to moderate cases as per the Ministry of Health and Family Welfare (MoHFW), Government of India guidelines [31].

\section{Patients excluded from study:}

- Patients with severe COVID-19 (fulfilling at least two of the following three criteria: respiratory distress at room ambience, i.e. $\geq 30$ breaths per min, oxygen saturation at rest $\leq 93 \%$ by peripheral digital arterial oximetry, and presence of any COVID-19 complications such as adult respiratory distress syndrome, respiratory failure, requirement of oxygen support or mechanical ventilation, septic shock, or severe nonrespiratory organ dysfunction or failure which may require admission in intensive care unit);

- Patients with co-morbidities such as diabetes mellitus, hypertension, cardiovascular disease, liver disease, chronic kidney disease, pulmonary disease, active carcinoma; history of immune suppression (solid organ or bone marrow transplant, use of immunosuppressive antimetabolic and biologic agents, intrinsic immunodeficiencies, HIV infection); history of bleeding hemorrhoids, hemoptysis and acid peptic disease;

- Patients on any AYUSH medications for COVID-19 like symptoms;

- Patients on parenteral nutrition;

- Patients with known sensitivity or contraindication to any of the ingredients of study intervention and pregnant or lactating women.

\section{Study Intervention}

AYUSH-64 (Batch no.:19-APM-LDA-175; Manufacturing date: April 2020; Expiry date: March 2023) two tablets (500 mg each) were administered three times daily with water after meals to the participants for 30 days along with standard conventional care in the AYUSH-64 add-on group. The control group received conventional care that included Paracetamol, Cetirizine, Vitamin C, and Azithromycin as per the clinical condition of the patient. Standard infection prevention and control practices such as respiratory and hand hygiene were followed in both groups. 
AYUSH-64 is a patent polyherbal formulation developed by the Central Council for Research in Ayurvedic Sciences (CCRAS), Ministry of Ayush, Government of India. AYUSH-64 consists of Saptaparna (Alstonia scholaris R. Br.), Katuki (Picrorhiza kurroa Royle ex. Benth), Kiratatikta (Swertia chirata Pexbex. Karst) and Kuberaksha (Caesalpinia crista L.). The composition details and quality standards of the trial drug are given in Tables 1 and 2. AYUSH-64 was procured from Indian Medicines Pharmaceutical Corporation Limited (IMPCL), Ministry of Ayush, Government of India. Quality control and safety parameters of the ingredients and the formulation complied with the Ayurveda Pharmacopoeia limits/in-house limits as appropriate.

\section{OUTCOMES MEASURES}

\section{Primary Outcome Measures}

The proportion of participants who attained clinical recovery and mean time (in days) to attain clinical recovery was the primary outcome measure. It was assessed by the Ayurveda physician on the basis of clinical features such as fever, cough, sore throat, nasal discharge, bodyache, headache, nausea, anorexia, diarrhea, abdominal pain, expectoration, chest pain and breathlessness on the planned follow-up visits scheduled on day 7, 15, 23, and 30 of the study period. The clinical recovery was confirmed as absence of any clinical symptoms of COVID-19.

\section{Secondary Outcome Measures}

The proportion of participants with negative RT-PCR assay for SARS-CoV-2 done on the "first day of clinical recovery" or "Day 10 after onset of symptoms" depending on whichever of the two time points were first achieved; change in laboratory parameters such as total and differential leukocyte count, inflammatory markers such as Interleukin-6 (IL-6), D-dimer, Creactive protein (CRP), Serum ferritin, Pro-calcitonin, Lactate dehydrogenase (LDH), Brain natriuretic peptide (BNP), Creatine kinase, Troponin I, Troponin $\mathrm{T}$ and change in HRCT chest. The laboratory investigations and HRCT chest were performed at Government approved facilities. The study design being open-label, the investigators/outcome assessors were not blinded to group allocation of participants.

\section{Safety Assessment}


Safety assessments included incidence of ADR/AE and change in liver function test and kidney function test at the end of the study period, that is day 30. All adverse events during the study were recorded and monitored as per Good Clinical Practice (GCP-ICH) guidelines.

\section{Sample Size}

The sample size for the study was calculated assuming that at the end of the study period, 80 per cent of the participants in the AYUSH-64 group and 50 per cent in the control group attain clinical recovery. In the absence of any previous data on these outcomes, our assumptions were based on clinical experience of the investigators. With a 95 per cent confidence level $(\alpha=0.05)$, power of 80 per cent, and assuming the attrition rate of 20 per cent, 40 participants were estimated to be enrolled in each group. Hence, a total of 80 participants were enrolled in the two groups of the study.

\section{Randomization}

Eighty eligible participants were randomized into two parallel groups in the ratio of 1:1. A statistician generated the random number sequences using the Statistical Package for Social Sciences version 15.0 (SPSS 15.0 for Windows, 233 South Wacker Drive, 11th Floor, Chicago, Illinois, U.S.A.).

\section{Ethical Consideration}

The study was conducted in accordance with ICMR's National Ethical Guidelines for Biomedical and Health Research on Human Participants (2017) The Institutional Ethics Committee of the host institute, reviewed, approved, and monitored the study. Participants provided written informed consent to participate in this study.

\section{Statistical Analysis}

The categorical variables have been summarized as numbers (percentage) and compared using the chi-square test. Continuous data have been represented as mean (standard deviation), except for data not following a normal distribution, which is presented as median (range). Analysis was done within each group and between the groups, using paired t-test and independent sample t-test for parametric data, Wilcoxon signed-rank test, and Mann-Whitney test for non-parametric data, 
respectively. A p <0.05 was considered significant. The per-protocol method was used for data analysis to ensure that the conclusions were based on patients receiving adequate study intervention. Data analysis was done using the STATA version 16.1 (Stata/MP 16.1 for Windows, Stata Corp, 4905 Lakeway Drive, College Station, Texas, US)

\section{RESULTS}

\section{Patient Enrolment}

Patient flow from screening to analysis is depicted in Figure 1. Total 90 RT-PCR confirmed COVID-19 patients were screened for study eligibility during the period of June 5, 2020 to July 16, 2020. After excluding ten patients [unwillingness to either come for follow-up ( $n=07)$, or complete the study period $(n=02)$, or participate $(n=01)], 80$ participants were enrolled on the next day of a positive RT-PCR test result. Two participants from each group dropped from the study (did not come for the first follow-up visit on day 7). One participant in each group withdrew from the study (reason: conception in the AYUSH-64 group, referral to higher medical care in the control group). Therefore, 37 participants each in the two study groups contributed to the final analysis.

\section{Baseline Characteristics of Study Participants}

The two study groups did not differ in baseline characteristics such as age, gender, and clinical severity (Table 3) and were comparable. The majority of participants were young males (mean age of 36.8 years in the AYUSH-64 group and 34.92 years in the control group). Clinically, majority of the participants (94.59 per cent in the AYUSH-64 group and 97.29 per cent in the control group) were mildly symptomatic with normal oxygen saturation level.

\section{Efficacy Outcomes}

The proportion of participants clinically recovered was significantly higher in the AYUSH-64 add-on group: on day 15, 62.2 per cent in the AYUSH-64 group and 13.5 per cent in the control group had recovered $(\mathrm{p}<0.001)$. The respective proportions were100 and 32.4 per cent on day 23 (Table 4). At the end of study period on day 30, all 37 participants in the AYUSH-64 add-on group had recovered clinically, compared to 54.1 per cent in the control group. The mean duration for clinical recovery in the AYUSH-64 add-on group $(5.8 \pm 2.67$ days $)$ was less as 
compared to the control group (10.0 \pm 4.06 days) on day 15 (Table 4$)$. The mean duration for clinical recovery was calculated on the basis of patient's data till day 15 as the enrolled participants were discharged on day 15 following the existing guidelines of local government authorities, and further follow-up visits were scheduled on day 23 and 30 of the study period. While majority of the participants (94.5 per cent) tested negative for COVID-19 (RT-PCR test) on day 15 in both groups, the time at which all participants tested negative was day 23 in the AYUSH-64 add-on group and day 30 in the control group (Table 4). However, these differences did not achieve statistical significance.Most inflammatory markers measured (IL-6, CRP, Serum ferritin, LDH, BNP, and Troponin T) reduced significantly $(\mathrm{p}<0.05)$ in both groups on day 30 . In the AYUSH-64 add-on group, significant reduction was also observed in D-dimer level, which was not observed in the control group (Table 6). The proportion of participants with improvement in HRCT chest was statistically significant in the AYUSH-64 add-on group $(\mathrm{p}=0.031)$ whereas it was statistically not significant in the control group $(\mathrm{p}=0.210)$ (Table 5). The participants with improved and worsening in the HRCT chest CO-RADS score were 15 and 05 respectively in the AYUSH-64 add-on group and 17 and 07 respectively in the control group. None of the participants required invasive or non-invasive oxygen therapy or developed complications such as pneumonia, acute respiratory distress syndrome, sepsis, and arrhythmia during the study period in the AYUSH-64 add-on group whereas one participant in the control group had progression of disease and required referral to a higher medical centre.

\section{Safety Outcomes}

In the AYUSH-64 add-on group, no ADR or SAE was observed or reported. However, one participant in the control group needed hospitalization at a higher medical centre due to progression of COVID-19 and hence dropped out from the study. The liver function tests and kidney function tests were found to be within the normal limits throughout the study period in both the groups.

\section{Discussion}

This open-label randomized, active-controlled study was conceptualized to explore the therapeutic efficacy and safety of AYUSH-64 as an add-on to standard care in the management of mild to moderate cases of COVID-19. 
The finding of early clinical recovery in patients receiving AYUSH-64 additional to standard care with over four times higher proportion of patients who recovered by day 15 (62 per cent versus 13 per cent, $\mathrm{p}<0.001)$ and lower mean time for clinical recovery (5.8 days versus 10 days)offers promise. The clinical improvement findings are supported by the observed significant improvement in several pro-inflammatory markers and CO-RADS scores for HRCT with the addition of AYUSH-64.

Other contemporary studies of AYUSH-64 for COVID-19 have also reported early clinical recovery and reduction in the levels of pro-inflammatory markers in asymptomatic and mild COVID-19 cases [32-33]. Reduction in the levels of pro-inflammatory markers indicates that AYUSH-64 could possibly arrest the inflammatory cascade, thereby seize or stop the progression of the disease to the severe or critical stage. Similarly, improved CO-RADS score in the AYUSH 64 group is favourable. Although this was a single-centre small-sized study, the finding that none of the participants required invasive or non-invasive oxygen support nor did any participant develop complications in the AYUSH-64 group, unlike one participant in the control group who had progression of the disease suggests the need for further exploration of AYUSH-64 in preventing the disease progression. Moreover, no ADR or SAE was observed or reported by any of the study participants in the AYUSH-64 group. This study furthers the findings of the established safety of AYUSH-64 [19, 20-23] by demonstrating its safety and tolerability when co-administered with conventional medicine and with less likelihood of drug-drug interactions.

This study is one of the early attempts at repurposing Indian traditional medicine for a newer disease such as COVID-19. So far, clinical studies on repurposing existing medications for COVID-19 included studies on Hydroxychloroquine, Favipiravir, Remdesivir and corticosteroids such as Dexamethasone. The outcomes of the clinical trial on Hydroxychloroquine do not recommend its use in the COVID-19 management [34]. Clinical studies on Remdesivir have also shown mixed or inconclusive results $[35,36]$. Dexamethasone has shown promising results in reducing mortality among severe COVID-19 patients [37]. Favipiravir has also been found effective in mild or moderate COVID-19 patients but has resulted in moderate elevation of hepatic transaminases [38]. Probably, Favipiravir, Remdesivir, and Dexamethasone are not the choice for treating asymptomatic and mild to moderate COVID-19 patients, with their known side-effects, if an alternative intervention with no such side-effects is available. With this analysis and background, this study could pave the way to positioning AYUSH-64 as a potential 
adjunct to standard care in the management of COVID-19. This has the potential to reduce the burden on hospital-based health care delivery system, especially important in this pandemic, which has overwhelmed the existing health-care system. Large multicentre studies with the use of AYUSH-64 are required. The Indian Ministry of Ayush has launched a nation-wide campaign for mass distribution of AYUSH-64 to asymptomatic, or mild to moderate cases of COVID-19 in home isolation [39]. Further, AYUSH-64 has also been incorporated in the National COVID management protocol based on Ayurveda and Yoga by the Government of India [18].

\section{Limitations of the Study}

Patients with mild to moderate COVID-19 were included in the study, therefore the findings could not be extrapolated to patients with severe infection or with co-morbidities. This was an open-label study at a single centre posing limitations to its findings being generalized.

\section{CONCLUSION}

AYUSH-64 as an adjunct to standard conventional care is safe and hastens clinical recovery from COVID-19 in patients with mild to moderate infection. The use of AYUSH-64 significantly improves pro-inflammatory markers such as IL-6, D-dimer, CRP, LDH, serum ferritin and HRCT chest score compared to standard care alone. Hence, AYUSH-64 can be considered as a safe and effective add-on intervention for the management of mild to moderate COVID-19.

\section{Trial Registration}

The trial was registered prospectively at the Clinical Trial Registry of India (CTRI/2020/05/025214).

\section{Source of Funding}

Central Council for Research in Ayurvedic Sciences, Ministry of AYUSH, Govt. of India

\section{Conflict of Interest}

The authors declare that they have no known competing interests. 


\section{REFERENCES}

[1] World Health Organization. WHO Coronavirus Disease (COVID-19) Dashboard. Available from: https://covid19.who.int/ (Accessed July 19, 2021)

[2] Srivastava P, Gupta N. Clinical manifestations of Corona Virus Disease. Clinical synopsis of COVID-19. 2020; 31-49. doi: 10.1007/978-981-15-8681-1_3.

[3] World Health Organization. Clinical management of COVID-19. Interim guidances; 27 May 2020.

[4] Centers for Disease Control and Prevention. COVID-19 information page (https://www.cdc.gov/coronavirus/2019-ncov/index.html).

[5] Wang Y, Zhang D, Du G, Du R, Zhao J, Jin Y, et al. Remdesivir in adults with severe COVID-19: a randomised, double-blind, placebo-controlled, multicentre trial. Lancet. 2020; 395(10236):1569-1578. doi: 10.1016/S0140-6736(20)31022-9.

[6] Horby P, Lim WS, Emberson JR, Mafham M, Bell JL, Linsell L, et al. Dexamethasone in hospitalized patients with Covid-19. N Engl J Med 2021;384(8):693-704. doi: 10.1056/NEJMoa2021436.

[7] Self WH, Semler MW, Leither LM, Casy JD, Angus DC, Brower RG, et al. Effect of Hydroxychloroquine on clinical status at 14 Days in hospitalized patients with COVID-19: A randomized clinical trial. JAMA. 2020;324(21):2165-2176. doi:10.1001/jama.2020.22240.

[8] Chaturvedi S, Kumar N, Tillu G, Deshpande S, Patwardhan B. AYUSH, modern medicine and COVID 19 pandemic. Ind J Med Ethics 2020;5(3): 191-5.

[9] Yang Y, Islam MS, Wang J, Li Y, Chen X. Traditional Chinese medicine in the treatment of patients infected with 2019-New Coronavirus (SARS-CoV-2): A review and perspective. Int J Biol Sci. 2020; 16(10):1708-1717. doi: 10.7150/ijbs.45538.

[10] Spelman K, Burns J, Nichols D, Winters N, Ottersberg S, Tenborg M. Modulation of cytokine expression by traditional medicines: A review of herbal immunomodulators. Altern Med Rev. 2006; 11(2):128-50.

[11] Roy A, Patwardhan B, Chaguturu R. Reigniting pharmaceutical innovation through holistic drug targeting. Drug Discov.World 2016; 17: 45-55.

[12] Rege AA, Chowdhary AS. Evaluation of some medicinal plants as putative HIV-protease inhibitors. Indian Drugs 2013;50:24-28 
[13] Burns JJ, Zhao L, Taylor EW, Spelman K. The influence of traditional herbal formulas oncytokine activity. Toxicology. 2010;278(1):140-59. doi:10.1016/j.tox.2009.09.020.

[14] Upadhyay AK, Kumar K, Kumar A, Mishra HS. Tinosporacordifolia (Willd.) Hook. f. and Thoms. (Guduchi) - validation of the Ayurvedic pharmacology through experimental and clinical studies. Int J Ayurveda Res2010; 1(2): 112-121.

[15] Sharma U, Bala M, Kumar N, Singh B, Munshi RK, Bhalerao S. Immunomodulatory active compounds from TinosporacordifoliaJ Ethnopharmacol2012 Jun 14; 141(3):918-26.

[16] Gandhi AJ, Rupareliya JD, Shukla VJ, Donga SB, Acharya R. An ayurvedic perspective along with in silico study of the drugs for the management of SARS-CoV-2. J Ayurveda Integr Med 2020. https://doi.org/10.1016/j.jaim.2020.07.002

[17] Maurya VK, Kumar S, Prasad AK, Bhatt ML, Saxena SK. Structure-based drug designing for potential antiviral activity of selected natural products from Ayurveda against SARS-CoV-2 spike glycoprotein and its cellular receptor. VirusDis2020; 31(2):179-193

[18] Ministry of Ayush, Government of India. National Clinical Management Protocol based on Ayurveda and Yoga for management of Covid-19. Available from: https://www.ayush.gov.in/docs/ayush-Protocol-covid-19.pdf; 2020 [accessed 17 May 2021].

[19]Gundeti MS, Bhurke LW, Mundada PS, Murudkar S, Surve A, Sharma R, et al. AYUSH-64, a polyherbalAyurvedic formulation in influenza like illness: results of a pilot study. J Ayurveda Integr Med 2020: S0975-9476(20)30025-5. doi: 10.1016/j.jaim.2020.05.010.

[20] Chari MV, Venkataraghavan S, Seshadri C, Shetty BR, Gowri N. A double blind clinical trial with Ayush-64 an Ayurvedic drug in P. vivax Malaria.Jour. Res. Ay. Sid. 1982; 6 (3-4): 105-116

[21] Bhatia D. Role of AYUSH-64 in malaria epidemic.Jour. Res. Ay. Sid. 1997; 18 (1-2): 7176.

[22] Pandey PN, Kishore P. Effect of Ayush-64 and SaptaparnaghanaVati on Microfilaraemia. Jour. Res. Ay. Sid. 1989; 12(3-4): 145-150.

[23] Anonymous.Management of chikungunya through Ayurveda and Siddha-A technical report.Central Council for Research in Ayurvedic Sciences, Department of Ayush, Ministry of Health \&Family Welfare, Govt. of India, 2009. 
[24] $\mathrm{Hu} \mathrm{TY}, \mathrm{Ju}$ JM, Mo LH, Ma L, Hu WH, You RR, et al. Anti-inflammation action of xanthones from Swertia chirayita by regulating $\mathrm{COX}-2 / \mathrm{NF}-\kappa \mathrm{B} / \mathrm{MAPKs} / \mathrm{Akt}$ signaling pathways in RAW 264.7 macrophage cells. Phytomedicine. 2019;55:214-221. doi: 10.1016/j.phymed.2018.08.001.

[25] Zhao YL, Shang JH, Pu SB, Wang HS, Wang B, Liu L, et al. Effect of total alkaloids from Alstoniascholaris on airway inflammation in rats. J Ethnopharmacol. 2016; 178:258-65. doi: 10.1016/j.jep.2015.12.022.

[26] Shukla S, Mehta A, Mehta P, Vyas SP, Shukla S, Bajpai VK. Studies on anti-inflammatory, antipyretic and analgesic properties of Caesalpinia bonducella F. seed oil in experimental animal models.FoodChemToxicol. 2010; 48(1):61-64. doi: 10.1016/j.fct.2009.09.015.

[27] Shukla S, Mehta A, Mehta P,Vyas SP, Shivaprasad HN. In vivo immunomodulatory activities of the aqueous extract of bonduc nut Caesalpinia bonducella seeds. Pharm Biol. 2010; 48(2):227-30. doi: 10.3109/13880200903085474.

[28] Kumar R, Gupta YK, Singh S, Raj A. Anti-inflammatory effect of Picrorhizakurroa in experimental models of inflammation. Planta Med. 2016; 82(16):1403-1409. doi: 10.1055/s0042-106304.

[29] Gupta A, Khajuria A, Singh J, Bedi KL, Satti NK, Dutt P, et al. Immunomodulatory activity of biopolymeric fraction RLJ-NE-205 from Picrorhizakurroa. IntImmunopharmacol. 2006;6(10):1543-9. doi: 10.1016/j.intimp.2006.05.002.

[30] Ram TS, Munikumar M, Raju VN, Devaraj P, Boiroju NK, Hemalatha R, et al. In silico evaluation of the compounds of the ayurvedic drug, AYUSH-64, for the action against the SARS-CoV-2 main protease.J Ayurveda Integr Med 2021. https://doi.org/10.1016/j.jaim.2021.02.004.

[31] Ministry of Health and Family Welfare, Government of India. Clinical Management Protocol: COVID-19.

[32] Reddy RG, Gosavi RV, Yadav B, Rai AK, Holay MP, Talekar M et al. AYUSH-64 as an add-on to standard care in asymptomatic and mild cases of COVID-19: A randomized controlled trial. 2021. Preprint available at: https://doi.org/10.31219/osf.io/pgraf 
[33] Thakar A, Goyal M, Bhinde S, Chhotala Y, Panara K, Chaudhari S. Efficacy of AYUSH-64 as add-on therapy in early stage COVID-19 - An open-label randomized controlled pilot study. 2021. Preprint available at: https://doi.org/10.31219/osf.io/t8wza

[34] Geleris J, Sun Y, Platt J, Zucker J, Baldwin M, Hripcsak G, et al. Observational study of hydroxychloroquine in hospitalized patients with Covid-19. N Engl J Med. 2020;382(25):24112418. doi: 10.1056/NEJMoa2012410.

[35] Wang Y, Zhang D, Du G, Du R, Zhao J, Jin Y, et al. Remdesivir in adults with severe COVID-19: Arandomized, double-blind, placebo-controlled, multicentre trial. Lancet. 2020;395(10236):1569-1578. doi: 10.1016/S0140-6736(20)31022-9.

[36] Grein J, Ohmagari N, Shin D, Diaz G, Asperges E, Castagna A, et al. Compassionate use of Remdesivir for patients with severe Covid-19. N Engl J Med. 2020;382(24):2327-2336. doi: 10.1056/NEJMoa2007016.

[37] RECOVERY Collaborative Group, Horby P, Lim WS, Emberson JR, Mafham M, Bell JL, et al. Dexamethasone in hospitalized patients with Covid-19. N Engl J Med. 2021;384(8):693704. doi: 10.1056/NEJMoa2021436.

[38] Dabbous HM, El-Sayed MH, El Assal G, Elghazaly H, Ebeid FFS, Sherief AF, et al. Safety and efficacy of favipiravir versus hydroxychloroquine in management of COVID-19: A randomized controlled trial. Sci Rep. 2021 Mar 31;11(1):7282. doi: 10.1038/s41598-021-852270 .

[39] Press Information Bureau, Government of India. Ayush Ministry launches nationwide distribution campaign of AYUSH-64 and KabasuraKudineer. 7th May 2021. Available from: https://pib.gov.in/Pressreleaseshare.aspx?PRID=1716729. 
Table 1: Composition of AYUSH-64 (each 500 mg capsule)

\begin{tabular}{|c|c|c|c|c|}
\hline S.No. & Name of the ingredient & Botanical name & Part used & Quantity \\
\hline 1. & $\begin{array}{c}\text { Saptaparna } \\
\text { (Aqueous extract) }\end{array}$ & Alstonia scholaris $\mathrm{R} . \mathrm{Br}$. & Bark & $100 \mathrm{mg}$ \\
\hline 2. & $\begin{array}{c}\text { Kutaki } \\
\text { (Aqueous extract) }\end{array}$ & $\begin{array}{c}\text { Picrorhiza kurroa Royle } \\
\text { ex. Benth }\end{array}$ & Rhizome & $100 \mathrm{mg}$ \\
\hline 3. & $\begin{array}{c}\text { Kiratatikta } \\
\text { (Aqueous extract) }\end{array}$ & $\begin{array}{c}\text { Swertia chirata Pexbex. } \\
\text { Karst }\end{array}$ & Whole plant & $100 \mathrm{mg}$ \\
\hline 4. & $\begin{array}{c}\text { Latakaranja } \\
\text { (seed powder) }\end{array}$ & Caesalpinia crista $\mathrm{L}$. & Seed & $200 \mathrm{mg}$ \\
\hline
\end{tabular}

Table 2: Quality Control Analysis of AYUSH-64

\begin{tabular}{|c|c|c|c|c|c|c|}
\hline \multirow{2}{*}{$\begin{array}{l}\text { S. } \\
\text { No. }\end{array}$} & \multirow[t]{2}{*}{ Test Parameters } & \multicolumn{4}{|c|}{ Ingredients } & \multirow[t]{2}{*}{ Formulation } \\
\hline & & $\begin{array}{l}\text { Saptaparna } \\
\text { (Aqueous } \\
\text { Extract) }\end{array}$ & $\begin{array}{l}\text { Kutaki } \\
\text { (Aqueous } \\
\text { Extract) }\end{array}$ & $\begin{array}{l}\text { Kiratatikta } \\
\text { (Aqueous } \\
\text { Extract) }\end{array}$ & $\begin{array}{l}\text { Latakaranja } \\
\text { (Seed Powder) }\end{array}$ & \\
\hline 1 & Loss on drying & NMT $9 \%$ & NMT $6 \%$ & NMT $8 \%$ & - & NMT $6 \%$ \\
\hline 2 & $\mathrm{pH}(1 \%$ Sol $)$ & $4.5-6.5$ & $4.0-7.0$ & $5.0-7.0$ & - & $4.0-6.5$ \\
\hline 3 & Total Ash & NMT $12 \%$ & NMT 5\% & NMT $15 \%$ & NMT 5\% & NMT $25.0 \%$ \\
\hline 4 & $\begin{array}{l}\text { Acid insoluble } \\
\text { Ash }\end{array}$ & NMT $2 \%$ & NMT $1 \%$ & NMT $2 \%$ & NMT $1 \%$ & NMT $8.0 \%$ \\
\hline 5 & $\begin{array}{l}\text { Alcohol soluble } \\
\text { extractive }\end{array}$ & NLT 3\% & NLT 3\% & NLT $12 \%$ & NLT $26 \%$ & NLT $5.0 \%$ \\
\hline 6 & $\begin{array}{l}\text { Water soluble } \\
\text { extractive }\end{array}$ & NLT $85 \%$ & NLT $80 \%$ & NLT $80 \%$ & NLT $4 \%$ & NLT $30.0 \%$ \\
\hline 7 & Heavy metals & \multicolumn{5}{|c|}{ Comply with API limits } \\
\hline 8 & TBC and YMC & \multicolumn{5}{|c|}{ Comply with API limits } \\
\hline 9 & Specific pathogens & \multicolumn{5}{|c|}{ Comply with API limits } \\
\hline 10 & Aflatoxins & \multicolumn{5}{|c|}{ Comply with API limits } \\
\hline 11 & Pesticide residue & \multicolumn{5}{|c|}{ Comply with API limits } \\
\hline
\end{tabular}

NMT: Not more than; NLT: Not less than; API: Ayurvedic Pharmacopoeia of India; TBC: Total Bacterial Count; YMC: Yeast \& Mould Count 
Table 3: Baseline clinical characteristics of the study participants $(n=74)$

\begin{tabular}{|c|c|c|c|c|}
\hline Variable & Parameters & $\begin{array}{c}\text { AYUSH-64 Group } \\
(n=37)\end{array}$ & $\begin{array}{c}\text { Control Group } \\
(n=37)\end{array}$ & $p$-value ${ }^{\$}$ \\
\hline Age: Mean (SD) & - & $36.86(12.30)$ & $34.92(11.94)$ & 0.492 \\
\hline \multirow{2}{*}{ Gender: n (\%) } & Male & $24(64.9)$ & $22(59.5)$ & \multirow{2}{*}{0.632} \\
\hline & Female & $13(35.1)$ & $15(40.5)$ & \\
\hline \multirow{2}{*}{$\begin{array}{c}\text { Clinical Severity } \\
\mathrm{n}(\%)\end{array}$} & Mild & 35 (94.59) & $36(97.29)$ & \multirow{2}{*}{0.555} \\
\hline & Moderate & $02(5.41)$ & $01(2.71)$ & \\
\hline $\mathrm{SpO}_{2}:$ Mean $(\mathrm{SD})$ & - & $97.49(1.32)$ & $97.14(1.39)$ & 0.270 \\
\hline
\end{tabular}

${ }^{\$}$ Compared using chi-square test

SD: Standard deviation SpO2: Oxygen saturation by pulse oximeter

Table 4: Results of clinical recovery and laboratory confirmation

\begin{tabular}{|c|c|c|c|c|}
\hline Outcome & & $\begin{array}{c}\text { AYUSH-64 Group } \\
(n=37)\end{array}$ & $\begin{array}{c}\text { Control Group } \\
(\mathbf{n}=37)\end{array}$ & $p$-value ${ }^{\mathrm{a}}$ \\
\hline \multirow{4}{*}{$\begin{array}{c}\text { Proportion of } \\
\text { participants clinically } \\
\text { recovered }\end{array}$} & Day 7 & $14(37.8 \%)$ & $2(5.4 \%)$ & $<0.001$ \\
\hline & Day 15 & $23(62.2 \%)$ & $5(13.5 \%)$ & $<0.001$ \\
\hline & Day 23 & $37(100.0 \%)$ & $12(32.4 \%)$ & - \\
\hline & Day 30 & $37(100.0 \%)$ & $20(54.1 \%)$ & 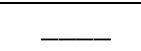 \\
\hline \multirow{4}{*}{$\begin{array}{c}\text { Proportion of } \\
\text { participants with } \\
\text { negative RT-PCR }\end{array}$} & Day 7 & $27(81.8)^{b}$ & $27(79.4)^{\mathrm{c}}$ & 0.803 \\
\hline & Day 15 & $35(94.5)$ & $35(94.5)$ & 0.999 \\
\hline & Day 23 & $37(100.0)$ & $36(97.29)$ & 0.314 \\
\hline & Day 30 & $37(100.0)$ & $37(100.0)$ & 0.999 \\
\hline
\end{tabular}

\footnotetext{
${ }^{\mathrm{a}}$ Compared using chi-square test / fisher exact test

${ }^{\mathrm{b}}$ Out of 33 participants (RT-PCR assay done on 33 out of 37 participants)

${ }^{\mathrm{c}}$ Out of 34 participants (RT-PCR assay done on 34 out of 37 participants)
} 
Table 5: Comparison of HRCT results

\begin{tabular}{|c|c|c|c|}
\hline Grading & & Baseline & 30 $^{\text {th }}$ Day \\
\hline \multirow[t]{3}{*}{ CO-RADS 1} & $\mathrm{AG}$ & $13(35.1 \%)$ & $20(54.1 \%)$ \\
\hline & $\mathrm{CG}$ & $8(21.6 \%)$ & $10(27.0 \%)$ \\
\hline & $p$-value ${ }^{\mathrm{a}}$ & 0.197 & $0.017 *$ \\
\hline \multirow[t]{3}{*}{ CO-RADS 2} & $\mathrm{AG}$ & $6(16.2 \%)$ & $5(13.5 \%)$ \\
\hline & $\mathrm{CG}$ & $9(24.3 \%)$ & $13(35.1 \%)$ \\
\hline & $p$-value ${ }^{\mathrm{a}}$ & 0.385 & $0.030^{*}$ \\
\hline \multirow[t]{3}{*}{ CO-RADS 3} & AG & $4(10.8 \%)$ & $3(8.1 \%)$ \\
\hline & $\mathrm{CG}$ & $5(13.5 \%)$ & $6(16.2 \%)$ \\
\hline & $p$-value ${ }^{\text {a }}$ & 0.722 & 0.285 \\
\hline \multirow[t]{3}{*}{ CO-RADS 4} & $\mathrm{AG}$ & $7(18.9 \%)$ & $4(10.8 \%)$ \\
\hline & $\mathrm{CG}$ & $5(13.5 \%)$ & $2(5.4 \%)$ \\
\hline & $p$-value ${ }^{a}$ & 0.596 & 0.394 \\
\hline \multirow[t]{3}{*}{ CO-RADS 5} & AG & $7(18.9 \%)$ & $5(13.5 \%)$ \\
\hline & $\mathrm{CG}$ & $10(27.0 \%)$ & $6(16.2 \%)$ \\
\hline & $p$-value ${ }^{\mathrm{a}}$ & 0.407 & 0.743 \\
\hline \multicolumn{4}{|c|}{${ }^{b}$ Within group $p$-value for $\mathrm{AG}=0.031 *$} \\
\hline \multicolumn{4}{|c|}{${ }^{b}$ Within group $p$-value for $\mathrm{CG}=0.210$} \\
\hline $\begin{array}{l}{ }^{\mathrm{a}} \text { Compared } \\
{ }^{\mathrm{b}} \text { Compared } \\
{ }^{*} p \text {-value of }< \\
\text { AG: AYUSH } \\
19 \text { Reporting }\end{array}$ & $\begin{array}{l}\text { r exact test } \\
\text { l Group; } \mathrm{H}\end{array}$ & computed to & RADS: COVID- \\
\hline
\end{tabular}


Table 6: Comparison of inflammatory markers

\begin{tabular}{|c|c|c|c|c|c|c|}
\hline $\begin{array}{l}\text { Parameters } \\
\text { (Reference range) }\end{array}$ & & Baseline & Day 7 & Day 15 & Day 30 & ${ }^{\text {a } p \text {-value }}$ \\
\hline \multirow{3}{*}{$\begin{array}{l}{ }^{c} \text { Interleukin-6 } \\
(0-7.00 \mathrm{pg} / \mathrm{mL})\end{array}$} & $\overline{A G}$ & $5.8(0.04,465.70)$ & $5.0(0.02,380.0)$ & $4.3(0.01,45.0)$ & $4.7(0.03,40.0)$ & 0.017 \\
\hline & CG & $4.4(0.08,38.29)$ & $8.0(0.05,48.90)$ & $2.8(0.01,37.50)$ & $4.5(0.03,32.60)$ & 0.006 \\
\hline & ${ }^{b} p$-value & 0.556 & & & 0.538 & \\
\hline \multirow{3}{*}{$\begin{array}{l}{ }^{\mathbf{c}} \text { C-Reactive protein } \\
(<6.0 \mathrm{mg} / \mathrm{dL})\end{array}$} & AG & $5.0(2,30)$ & $4.0(2,47)^{*}$ & $3.9(2.4,35.0)^{*}$ & $3.7(2,33)^{*}$ & $<0.001$ \\
\hline & CG & $5.0(2,35)$ & $4.0(1,22)^{*}$ & $4.0(2.5,28.8)$ & $3.8(2,19)^{*}$ & $<0.001$ \\
\hline & b-value & 0.392 & & & 0.566 & \\
\hline \multirow{3}{*}{ 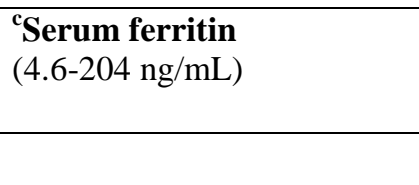 } & AG & $86.7(9,1500)$ & $93.0(6,1500)^{*}$ & $73.4(8,1428)^{*}$ & $59.0(4,1400)^{*}$ & $<0.001$ \\
\hline & CG & $109.5(6,618)$ & $105.3(6,560)^{*}$ & $81.4(5,489)^{*}$ & $76.0(6,515)^{*}$ & 0.009 \\
\hline & ${ }^{b} p$-value & 0.685 & & & 0.433 & \\
\hline \multirow{3}{*}{$\begin{array}{l}{ }^{d} \mathbf{D} \text {-dimer } \\
(0-0.5 \mu \mathrm{g} / \mathrm{mL})\end{array}$} & AG & $0.35(0.211)$ & $0.36(0.301)$ & $0.26(0.115)$ & $0.21(0.115)^{*}$ & 0.007 \\
\hline & CG & $0.34(0.176)$ & $0.33(0.401)$ & $0.35(0.168)$ & $0.24(0.146)$ & 0.129 \\
\hline & b $p$-value & 0.484 & & & 0.134 & \\
\hline \multirow{3}{*}{$\begin{array}{l}{ }^{\mathrm{d}} \text { Pro-calcitonin } \\
(<0.05 \mathrm{ng} / \mathrm{mL})\end{array}$} & AG & $0.02(0.014)$ & $0.02(0.014)$ & $0.04(0.078)$ & $0.02(0.008)$ & 0.159 \\
\hline & CG & $0.06(0.127)$ & $0.05(0.112)$ & $0.02(0.011)$ & $0.02(0.009)$ & 0.102 \\
\hline & ${ }^{b} p$-value & 0.004 & & & 0.296 & \\
\hline \multirow{3}{*}{$\begin{array}{l}{ }^{\mathrm{d}} \text { Lactate dehydrogenase } \\
(134-214 \mathrm{U} / \mathrm{L})\end{array}$} & AG & $171.90(15.100)$ & $160.30(15.013)^{*}$ & $155.55(11.168)^{*}$ & $151.81(14.001)^{*}$ & $<0.001$ \\
\hline & CG & $174.58(13.580)$ & $158.94(12.767)^{*}$ & $158.55(9.263)^{*}$ & $153.99(9.761)^{*}$ & $<0.001$ \\
\hline & b p-value & 0.295 & & & 0.083 & \\
\hline \multirow{3}{*}{$\begin{array}{l}{ }^{\mathrm{d}} \text { Creatine kinase } \\
(0-25 \mathrm{U} / \mathrm{L})\end{array}$} & AG & $15.69(3.758)$ & $13.76(2.952)^{*}$ & $12.99(3.026)^{*}$ & $11.61(2.251)^{*}$ & \\
\hline & CG & $15.33(3.885)$ & $13.29(2.708)^{*}$ & $13.20(1.928)^{*}$ & $11.77(2.198)^{*}$ & $<0.001$ \\
\hline & ${ }^{b} p$-value & 0.970 & & & 0.503 & \\
\hline \multirow{3}{*}{$\begin{array}{l}\text { 'B-type natriuretic peptide } \\
(<300 \mathrm{pg} / \mathrm{ml})\end{array}$} & AG & $180.0(134,1475)$ & $170.0(140,475)$ & $160.0(122,450)$ & $160.0(135,750)$ & $<0.001$ \\
\hline & CG & $177.0(136,625)$ & $160.0(17,265)$ & $158.0(111,190)$ & $157.0(130,199)$ & $<0.001$ \\
\hline & ${ }^{b} p$-value & 0.138 & & & 0.766 & \\
\hline \multirow{3}{*}{$\begin{array}{l}{ }^{\mathrm{d}} \text { Troponin I } \\
(0.00-0.02 \mathrm{ng} / \mathrm{mL})\end{array}$} & AG & $0.005(0.002)$ & $0.004(0.002)^{*}$ & $0.004(0.002)$ & $0.003(0.001)^{*}$ & $<0.001$ \\
\hline & CG & $0.005(0.003)$ & $0.003(0.002)$ & $0.005(0.007)$ & $0.003(0.002)$ & 0.132 \\
\hline & ${ }^{b} p$-value & 0.280 & & & $<0.001$ & \\
\hline \multirow{2}{*}{$\begin{array}{l}\mathrm{d}^{\mathrm{T}} \text { Troponin T } \\
(\leq 14.0 \mathrm{ng} / \mathrm{mL})\end{array}$} & AG & $7.68(1.447)$ & $6.45(1.276)^{*}$ & $5.83(1.108)^{*}$ & $5.53(0.814)^{*}$ & $<0.001$ \\
\hline & CG & $7.44(1.475)$ & $6.30(0.975)^{*}$ & $6.049(0.978)^{*}$ & $5.56(0.985)^{*}$ & $<0.001$ \\
\hline
\end{tabular}

\footnotetext{
${ }^{\mathrm{a}}$ Within group p-value; ${ }^{\mathrm{b}}$ Between group p-value compared using independent sample t-test; ${ }^{\mathrm{c}}$ Reported as Median (Min, Max) and compared within group using Friedman test; ${ }^{\mathrm{d}}$ Reported as Mean (SD) and compared within group using Repeated measure ANOVA; *p-value $<0.05$ on comparison with baseline; AG: AYUSH-64 group; CG: Control group
} 
Excluded $(\mathrm{n}=10)$

- Not willing to come for follow-up $(n=07)$

- Not willing to complete the study period $(\mathrm{n}=02)$

- Not willing to participate in the study $(\mathrm{n}=01)$

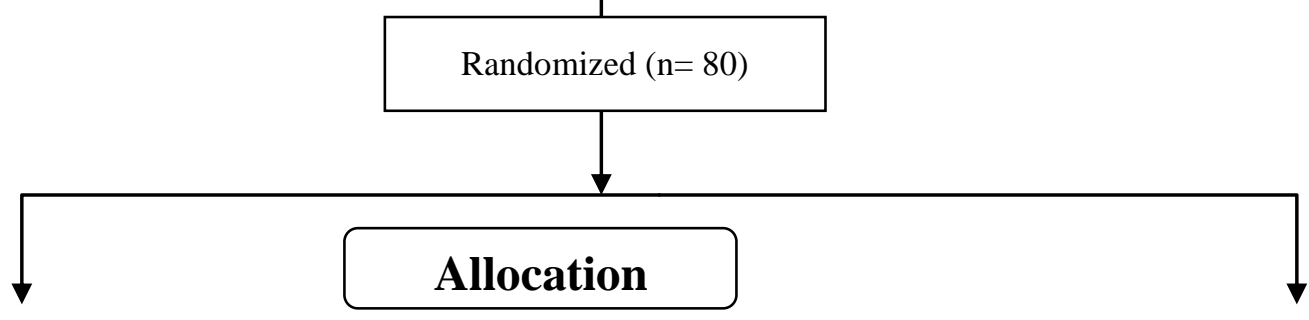

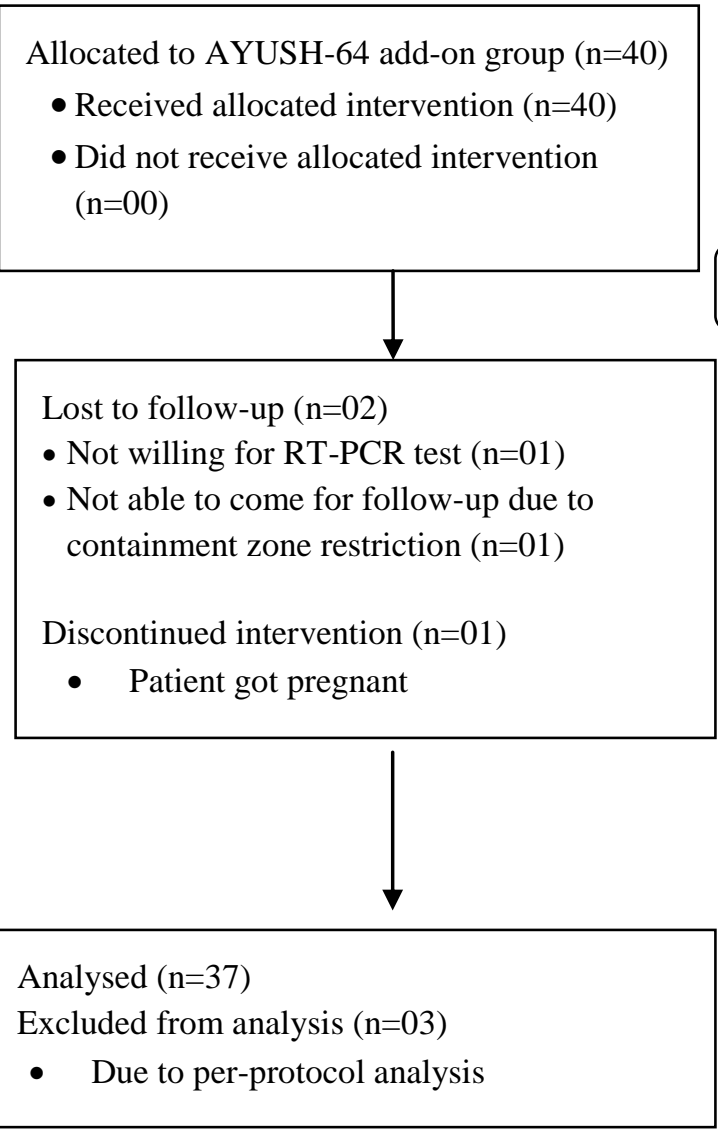

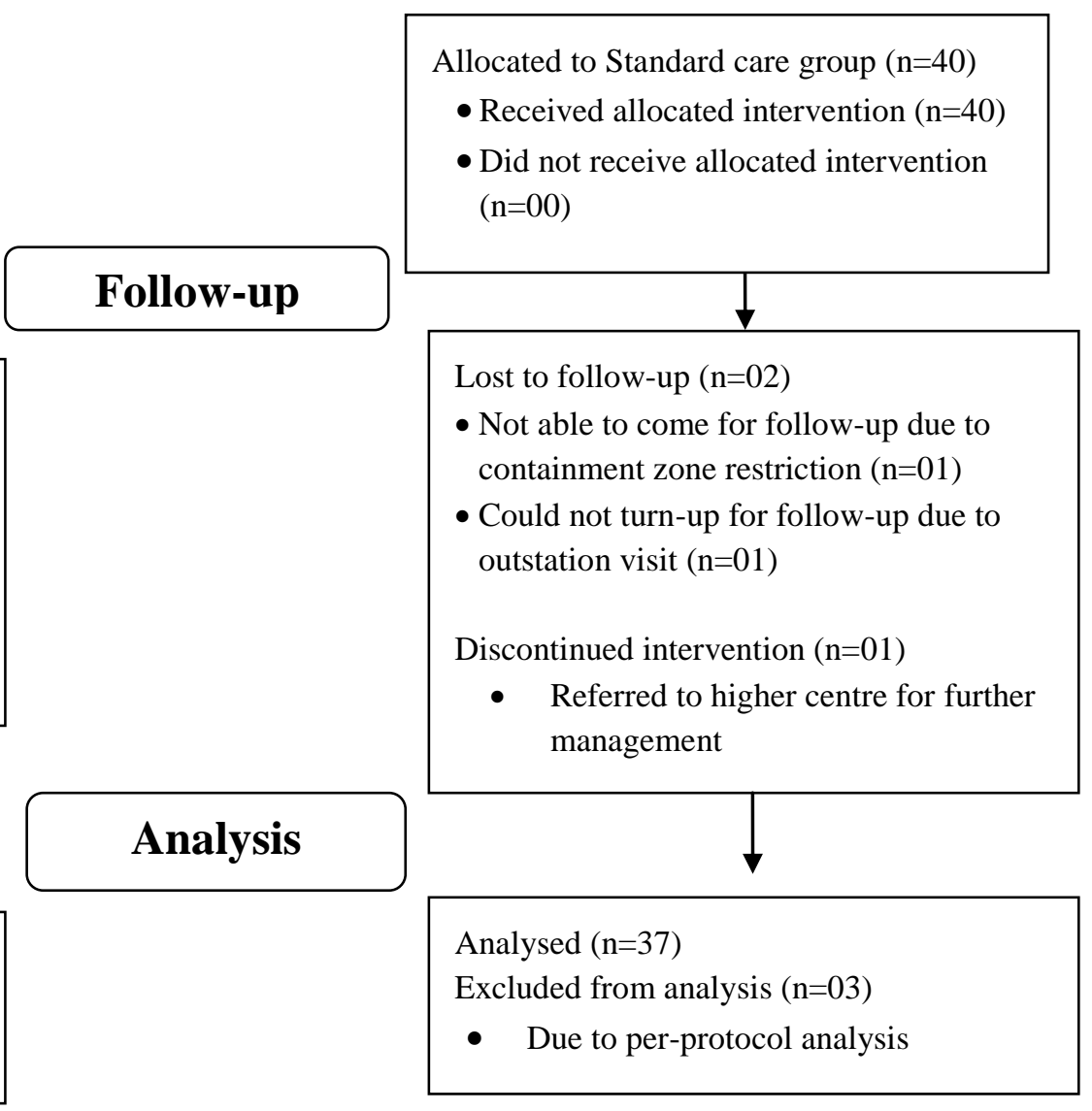

Figure 1: CONSORT Flow Diagram 